\title{
Ecosystem equivalence and the ability to generalise: insights from global consistencies in mangrove fish assemblages
}

\author{
Marcus Sheaves* \\ Centre for Tropical Water and Aquatic Ecosystem Research, School of Marine and Tropical Biology, James Cook University, \\ Townsville, Queensland 4811, Australia
}

\begin{abstract}
It is common practice in ecology to extrapolate understanding of processes and functions from one example of an ecosystem to another. Valid extrapolation requires an assumption of ecosystem equivalence, i.e. that the different examples of the ecosystem are actually similar in regard to the understanding being extrapolated. I use the example of mangrove fish assemblages to assess ecosystem equivalence using data compiled from 76 studies from around the world. Although there were distinct fish faunal groups (FGs) in different areas of the world, there was evidence of underlying faunal equivalence. Mangrove fish comprised a restricted pool of $170 \mathrm{fam}-$ ilies, with 41 of those occurring in all 4 FGs. Whether studies only considered fish actually entering mangrove forests or included associated habitats was not an important factor for differentiating assemblages. This suggests that from a fish perspective, the mangrove ecosystem is defined at a whole-of-mangrove system level rather than the scale of the mangrove forest. There were notable differences among families that distinguished the different FGs, but these differences did not translate into functional differences. Although the results appear to provide a degree of validity for extrapolating understanding of processes and functions from one example of an ecosystem to another, this implied support must be set in the context of the limitations of the available data. Indepth evaluation of ecosystem equivalence is urgently needed because this untested assumption is central to the validity of every model or interpretation based on data from a distant location.
\end{abstract}

KEY WORDS: Ecosystem equivalence - Ecosystem · Mangrove · Fish · Global distribution · Community composition

Resale or republication not permitted without written consent of the publisher

\section{INTRODUCTION}

Ecology is deeply concerned with understanding the processes that drive the predictable patterns we see in species, assemblages and communities. The very complexity of nature means that we must make the task manageable by breaking down the diversity of life, its interacting links, the systems that support it and the physical environment in which the supporting processes are set, into smaller logical units. For many purposes, the logical subdivision is the ecosystem (Tansley 1935), a biotic community or assemblage and its associated physical environment in a specific place.
The ecosystem concept is critical to everyday ecological practice. The idea of an ecosystem as a unit with defined properties (Lamont 1995, O'Neill 2001) forms the implicit basis for extrapolating understanding of processes and functions from one example of an ecosystem to another. The importance of such extrapolation is apparent when considering how often ideas, models, values, etc., derived from a particular ecosystem in one part of the world, are used as a basis for understanding a 'similar' ecosystem in other parts of the world. This ranges from the extraction of parameters for ecological models, through explanations of pattern and process, to support or refutation for alternative explanations for observa- 
tions; things we have all done many times. However, valid extrapolation requires an assumption of ecosystem equivalence, i.e. that the different examples of the ecosystem in question are actually similar in regard to the understanding being extrapolated. Obviously, we must be clear about the limits of our understanding whenever we extrapolate (Rothchild 2006). This becomes more of an imperative when that extrapolation involves ecosystem units that may be thousands of kilometres apart. Despite the importance of ensuring that such extrapolations are valid, there are few examples where the assumption of ecosystem equivalence has been evaluated or even explicitly stated. Most studies that have touched on ecosystem equivalence have done so while pursuing other specific aims, and the implications of their results for equivalence are varied. For instance, Bellwood (1996) showed global consistency in taxonomic composition of coral reef fish fauna when he developed his reef fish consensus list, and Fuentes (1976) found ecological convergence between taxonomically unrelated lizard communities in Chile and California. In contrast, Smith et al. (1989) detected global variations in mangrove propagule predation, while Winterbourn et al. (1981) showed that the functioning of New Zealand streams was not consistent with the river continuum concept (Vannote et al. 1980) that was the dominant paradigm for North American streams at the time. There are other relevant examples, but together, they do not represent a significant body of work compared to what is required to validate or invalidate the practice of extrapolating understanding of processes and functions among spatially disparate examples of ecosystem types.

Equivalent ecosystems would need to function similarly, contain habitats that provide similar services to biota, and have similar roles performed by the taxonomic and functional groups that occupy them. At a more tractable level, ecosystem equivalence assumes the occurrence of similar biotic components; biologists talk about the avifauna of boreal forest ecosystems (e.g. Cheng et al. 2010) or the benthic epifauna of abyssal plain ecosystems (e.g. Amaro et al. 2010), under the tacit understanding that we are considering functionally and largely taxonomically equivalent assemblages in each case. This assumption seems reasonable because the idea of an ecosystem type suggests a particular set of underlying processes and functional roles (O'Neill 2001), so it seems logical that this particular set of roles is most likely to be fulfilled by similar organisms.

But how consistent are ecosystem-specific faunal assemblages? What do any differences mean for ecosystem function? I address these questions using the example of the fish assemblages of mangrove ecosystems. Similar functions are attributed to mangrove ecosystems throughout the world, but recently, the global applicability of one critical function, the provision of nursery grounds for nekton (Nagelkerken et al. 2000, Sheaves et al. 2006), has come into question (Dorenbosch et al. 2005, Hammerschlag et al. 2010), making the mangrove ecosystem an interesting test subject. Specifically, I deal with 4 questions: (1) Is there a characteristic global mangrove fish assemblage, and if so, what are its characteristic components, patterns of dominance and functional attributes? (2) Is there substantial systematic variation in mangrove fish assemblages or their functioning around the world, and if so, what is the pattern of variation? (3) What do these similarities and differences mean for ideas of faunal equivalence and an identifiable 'mangrove ecosystem'? (4) What are the implications for extrapolation of functional understanding from one ecosystem unit to another?

\section{MATERIALS AND METHODS}

I reviewed the international literature relating to mangrove ecosystems. I considered studies in which the system in question was described as a mangrove system or could be identified as such. I collected data from all available studies that appeared to report complete fish species lists, either directly or as part of auxiliary material. The resulting data set comprised studies from around the world. However, its diverse derivation presented a range of difficulties, some of which were addressed at least partially by the inclusion of explanatory variables and some that required specific assumptions (see Supplement S1 at www. int-res.com/articles/suppl/m461p137_supp.pdf). Overall, there were many sources of random or unexplained variation. It was assumed that any variation that could not be accounted for with explanatory variables would have the effect of making underlying patterns less distinct, so the expectation was that any strong patterns that were detected would indicate robust outcomes despite the masking variation.

\section{Data analyses}

Data were collected on the number of species in each family from 76 studies (Table 1; see Supplements 2 \& 3 at www.int-res.com/articles/suppl/ m461p137_supp.pdf) that fit the criteria of (1) relat- 
Table 1. Spatial distribution of studies and faunal group (FG) structure determined using multivariate classification and regression tree (mCART) analysis. EC: eastern central

\begin{tabular}{|c|c|c|c|c|}
\hline Country & Area & Area Code & Data sets & FG \\
\hline Brazil & North Brazil & N Brazil & 3 & EC Atlantic \\
\hline Brazil & Southeast Brazil & SE Brazil & 1 & EC Atlantic \\
\hline Mexico & West Mexico & Mexico & 1 & EC Atlantic \\
\hline Benin & West Africa & W Africa & 1 & EC Atlantic \\
\hline Gambia & Northwest Africa & NW Africa & 8 & EC Atlantic \\
\hline Nigeria & West Africa & W Africa & 2 & EC Atlantic \\
\hline Senegal & Northwest Africa & NW Africa & 2 & EC Atlantic \\
\hline Australia & Northwest Australia & NW Australia & 2 & Australasian \\
\hline Australia & Tropical Northeast Australia & TN Australia & 10 & Australasian \\
\hline Philippines & East Asia & E Asia & 2 & Australasian \\
\hline S Africa & South East Africa & SE Africa & 2 & Australasian \\
\hline Singapore & Indochina & Indochina & 1 & Australasian \\
\hline Taiwan & East Asia & E Asia & 3 & Australasian \\
\hline Thailand & Indochina & Indochina & 2 & Australasian \\
\hline Vietnam & East Asia & E Asia & 1 & Australasian \\
\hline Belize & Belize & Belize & 2 & Caribbean \\
\hline Curacao & Caribbean & Caribbean & 2 & Caribbean \\
\hline Lesser Antilles & Caribbean & Caribbean & 1 & Caribbean \\
\hline Puerto Rico & Caribbean & Caribbean & 3 & Caribbean \\
\hline USA & Southeast USA & USA & 11 & Caribbean \\
\hline Australia & Subtropical Australia & ST Australia & 10 & Central Indo-Pacific \\
\hline Bangladesh & Indian subcontinent & India & 1 & Central Indo-Pacific \\
\hline Sri Lanka & Indian subcontinent & India & 1 & Central Indo-Pacific \\
\hline A Samoa & Pacific Island Countries & $\mathrm{PIC}$ & 1 & Central Indo-Pacific \\
\hline Borneo & Borneo (Sulawesi) & Borneo (Sulawesi) & 1 & Central Indo-Pacific \\
\hline Fiji & Pacific Island Countries & PIC & 1 & Central Indo-Pacific \\
\hline Kenya & East Africa & E Africa & 6 & Central Indo-Pacific \\
\hline Madagascar & Madagascar & Madagascar & 1 & Central Indo-Pacific \\
\hline New Caledonia & Pacific Island Countries & PIC & 1 & Central Indo-Pacific \\
\hline PNG & Papua New Guinea & PNG & 5 & Central Indo-Pacific \\
\hline Solomon & Pacific Island Countries & PIC & 1 & Central Indo-Pacific \\
\hline Sulawesi & Borneo (sulawesi) & Borneo (Sulawesi) & 2 & Central Indo-Pacific \\
\hline Tanzania & East Africa & E Africa & 1 & Central Indo-Pacific \\
\hline W Samoa & Pacific Island Countries & PIC & 1 & Central Indo-Pacific \\
\hline Australia & Southeast Australia & SE Australia & 3 & Central Indo-Pacific \\
\hline Papua New Guinea & West Papua & W Papua & 3 & Central Indo-Pacific \\
\hline
\end{tabular}

ing to mangrove ecosystems and (2) reporting complete fish species lists. These data were standardised by the total number of species per study to produce a dependent variable data set comprising the proportion of the total species pool for each study contributed by each family. The 76 studies covered 32 countries (Fig. 1) and provided 99 independent data sets. The studies were grouped into 22 areas (Table 1) based on geographic proximity to produce a spatial explanatory variable set compact enough for analysis. In most cases, these formed natural groups within a radius of $\sim 1000 \mathrm{~km}$. Where there was a continuum rather than a natural split, differentiation was based on recognised geographic divisions (e.g. northeastern Australian sites separated into tropical and sub-tropical at the Tropic of Capricorn). These were reasonably consistent with the 'large marine ecosys- tems' of Sherman \& Aquarone (2004) but were often smaller in spatial extent.

\section{Patterns of similarity and difference}

The similarities of mangrove fish assemblages around the world, regional grouping structure and the importance of additional explanatory variables were analysed with a multivariate classification and regression tree (mCART) (De'ath 2002), based on Bray-Curtis dissimilarity using the mvPART package in R software (De'ath 2012). The dependent variables were the relative number of species per family (i.e. percentage of total numbers of species for each of the 99 data sets) for families occurring in $>5 \%$ of the data sets. The selection of the final tree models was con- 


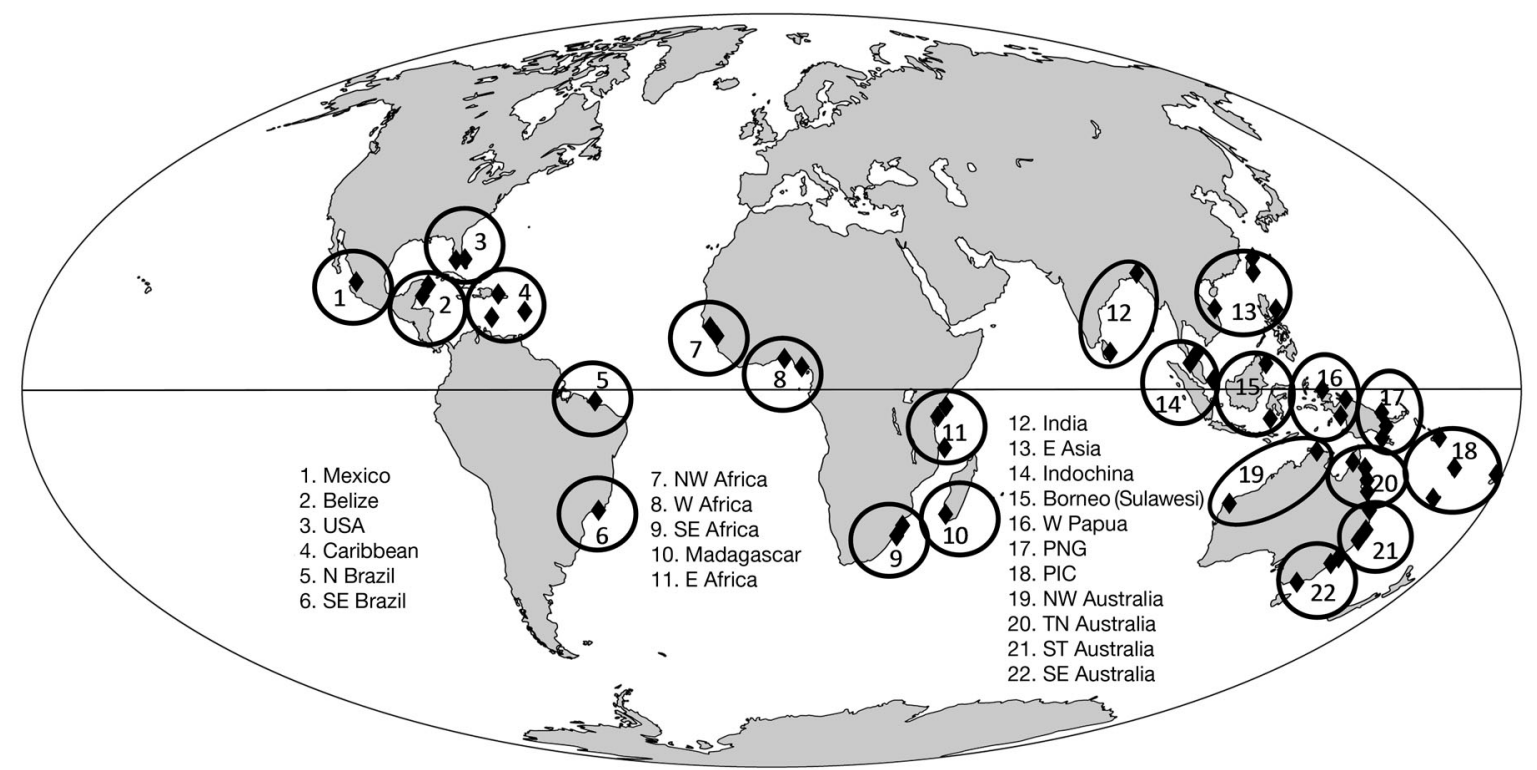

Fig. 1. Locations of mangrove fish studies ( $\bullet$ and the 22 area groupings (ellipses)

ducted using 10-fold cross validation, with the 1-SE tree (the smallest tree with cross validation error within 1 standard error [SE] of that of the tree with the minimum cross validation error) selected as the final tree model, a procedure that produces valid, biologically interpretable trees (Breiman et al. 1984, De'ath 2002). The impact of each variable on model structure was evaluated by its occurrence in the final 1-SE tree. Additionally, the 'relative importance' of variables was assessed to ensure variables that had high overall importance, but were not the best predictors for particular splits, were not overlooked. Importance is determined by using each variable at each branching of the final tree, with the best overall classifier given a relative importance of $100 \%$. The predictor variables were: area, mangrove system type (estuarine [small proportion of area freshwater influenced], riverine [includes large area of freshwater influenced mangroves and possibly nonmangrove areas], coastal, bar-built lagoonal, reefal, mixed or undefinable), tide range (calculated from database courtesy J. Chittleborough, Australian National Tidal Centre), sampling target (mangroves only vs. whole-of-mangrove system), system scale (small, medium, large or very large), and sampling gear type (e.g. gill nets, seine nets, beam trawls or stake nets).

The mCART analysis defined 4 distinct faunal groups (FGs). Families that discriminated among the 4 mangrove fish FGs defined by the mCART were assessed using indicator analysis (Dufrene \& Legendre 1997), with the significance of indicator groups tested using 1000 Monte Carlo permutations.
A family that was a perfect indicator (i.e. an indicator value [IV] of $100 \%$ ) of an FG would be one that occurred only in that FG and in all data sets from that FG. Families with maximum indicator values (mIVs) $\geq 30 \%$ (all significant at $p \leq 0.04$ ) were considered 'indicative' of an FG. Family summaries by Froese \& Pauly (2010) were used to establish whether indicative families had widespread (recorded as occurring in most parts of the world where mangroves are found) or restricted distributions. Homogeneity of proportions were compared across the FGs using a randomisation test of independence (RTI) (McDonald 2009), a simple permutation test (1000 iterations) using a $\chi$-statistic.

The primary non-mangrove ecosystem affinities (freshwater, coastal, reef) of common mangrove families (occurring in $>25 \%$ of studies in any FG) were assessed based on information reported by Froese \& Pauly (2010). Again, ambiguities were accounted for with reference to the body of literature reviewed. The homogeneity of proportions of common mangrove families in each FG with the various non-mangrove affinities were compared using RTI (McDonald 2009). To further investigate the degree to which mangrove fish families overlapped with families characteristic of coral reefs, the occurrence of common mangrove families in Bellwood's (1996) coral reef fish family consensus list were evaluated for each FG. Bellwood's (1996) consensus list represents one of the few attempts to define a characteristic marine fauna and provides a useful reference point because it relates to families characteristic of another dominant shallow water tropical marine ecosystem. 


\section{Functional comparisons among the FGs}

Patterns of trophic dominance among FGs were evaluated for common mangrove families. Trophic role assessment was based on the dominant role of the family reported by Froese \& Pauly (2010). Where a range of trophic roles was reported, the evaluation was modified in line with information from the literature reviewed that was specific to the genera inhabiting mangroves. The homogeneity of proportions of common families in 7 trophic categories (feeders on macrobenthos, microinvertebrates, nekton, phyto-detritus, plankton, algae and/or microinvertebrates or coral) across the FGs was evaluated using an RTI (McDonald 2009). The main habit (benthic: sedentary bottom associated; demersal: active bottom associated; bentho-pelagic: occurring at a range of depths but not predominantly pelagic or demersal; pelagic: consistently found in surface or midwater) of each common mangrove family was evaluated in a similar way, and the homogeneity of proportions was compared among the FGs using an RTI (McDonald 2009).

To investigate the consistency of functional attributes of mangrove fish assemblages, the distribution of feeding strategies of one trophic group, nekton feeders, was compared among FGs. Four broad strategy categories (see Supplement S4 at www.int-res.com/articles/suppl/m461p137_supp.pdf) were defined: ambush predators (either attacking from cover, e.g. buried in sediment, or using camouflage), foragers (predators, primarily associated with benthic environments, that move freely searching for prey, which they catch more by stealthy approach, followed by a short attacking burst, rather than by running down their prey), cursorial (usually pelagic or mid-water predators that predominantly feed on prey in open water that they actively chase and capture) and static habituators (remain motionless or very slow moving in open water in a non-threatening manner, allowing prey to approach to a point where a rapid lunging attack is initiated). This is, of course, a very approximate definition of predatory strategies because a range of strategies may be employed within a family or even a species. The evaluation was based on information reported by Froese \& Pauly (2010) with ambiguities accounted for with reference to the literature reviewed. Analysis was again based on common mangrove families. The homogeneity of proportions of nekton feeders in the 4 strategy categories across the FGs was evaluated using an RTI (McDonald 2009).

\section{RESULTS}

The 99 data sets include a total of 170 families of fish (see Supplement S3 at www.int-res.com/articles/ suppl/m461p137_supp.pdf). Despite the many potential sources of variation in the data set, mCART produced a final 4 -leaf tree that explained $43 \%$ of the total variation in the data set (Fig. 2). All of the splits in the final tree were due to 'area', with no other predictor variables contributing to model explanation. Area also had the highest relative importance (by definition 100\%), with tidal range the next most important $(65 \%)$. Other potential sources of variation had low relative importance (gear type: $52 \%$, system scale: $37 \%$, system type: $18 \%$, sampling target: $8 \%$ ), indicating that the patterns in family structure were robust despite these potentially complicating factors.

\section{Patterns of similarity and difference}

There was a major separation in mangrove fish fauna between ocean basins. The initial mCART split segregated all of the Indo-Pacific areas, except the single sample from Mexico's Pacific seaboard, from all of the Atlantic sites (Figs. 2 \& 3). Subsequent splits delineated 4 FGs: Eastern Central Atlantic (EC Atlantic), Caribbean, Central Indo-Pacific (Central IP) and Australasian. The inclusion of western Mexican area as part of the EC Atlantic FG must be interpreted with caution; the Mexican data come from a single study, so there was no opportunity for it to group with other geographically similar sites, making it impossible to infer any particular meaning from its grouping with the Atlantic sites.

The 2 Atlantic FGs were spatially separated (except for the inclusion of Mexican sites in the EC Atlantic FG) (Fig. 3) and featured discrete groups of indicator families (IVs $>30 \%$ ) usually having low indicator values for other FGs or being totally absent from them (Fig. 4). The EC Atlantic FG was characterised by Families Sciaenidae, Cichlidae, Elopidae, Polynemidae, Eleotridae, Ariidae, Clupeidae, Pristigasteridae, Mugillidae and Claroteidae, while the Caribbean FG (Fig. 4b) featured high indicator values for Cyprinodontidae, Scaridae, Lutjanidae, Gerreidae, Pomacentridae, Poeciliidae, Haemulidae, Sparidae and Chaetodontidae. The Indo-Pacific FGs showed more complex relationships: rather than forming single spatially discrete areas, the FGs formed a mosaic of patches. This complexity was reflected by considerable overlap among the indica- 


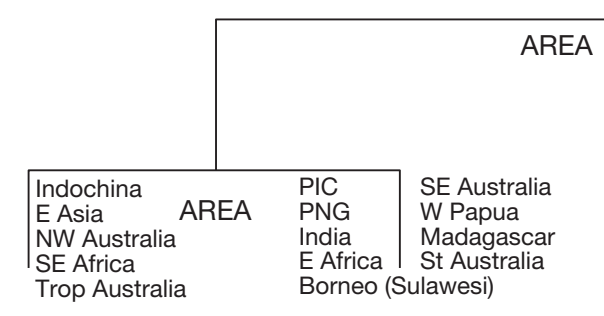

(23)

Australasian
(39)

Central IP

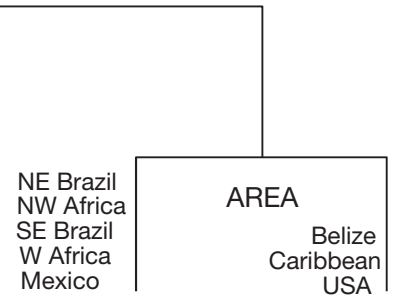

(18)

EC Atlantic

Hemiramphidae, Kyphosidae and Mullidae; however, many families also found in the Australasian FG had moderate indicator values (20 to $30 \%$ ).

Even though 4 FGs could be differentiated on the basis of indicator families that characterised the differences among FGs, there were 41 families that occurred in all 4 FGs (Fig. 5). Many of these were reported from a substantial proportion of studies in all FGs and could be considered as a core group typical of mangrove ecosystems around the world.

There were clear differences in the mixtures of widespread families and families with restricted distributions $\left(\chi^{2}=14.51, \mathrm{df}=3, \mathrm{p}=0.0006\right)$ among the FGs with high indicator values (mIV

tor groups (Fig. 4c,d), with the Australasian and Central IP FGs having similar compliments of families but differing in the strength of indication of those families. The Australasian FG included tropical Australia, mainland south-east Asian and south-east African sites, with 8 families showing high indicator values (Fig. 4c): Leiognathidae, Ambassidae, Terapontidae, Scatophagidae, Sillaginidae, Platycephalidae, Gobiidae and Siganidae. The Central IP group comprised sites from across the central part of the Indo-Pacific region (Fig. 3) including most island sites together with eastern African, Indian and sub-tropical and temperate Australian sites. There were only 4 families with high indicator values (Fig. 4d): Apogonidae, $\geq 30 \%$ ). The EC Atlantic and Caribbean FGs showed a dominance of widespread families and small contribution from families with restricted distributions (Fig. 6). Widespread taxa completely dominated the small group of highly indicative families in the Central IP FG, but the situation was reversed for the Australasian FG, where most of the highly indicative families had restricted distributions.

Substantial differences $\left(\chi^{2}=13.93\right.$, df $=6, p=$ $0.0234)$ in the non-mangrove affinities of the common mangrove families (occurring in $>25 \%$ of studies in any FG) typical of the 4 FGs provide insight into the faunal characteristics underlying differences and similarities among FGs (Fig. 7). Despite taxo-

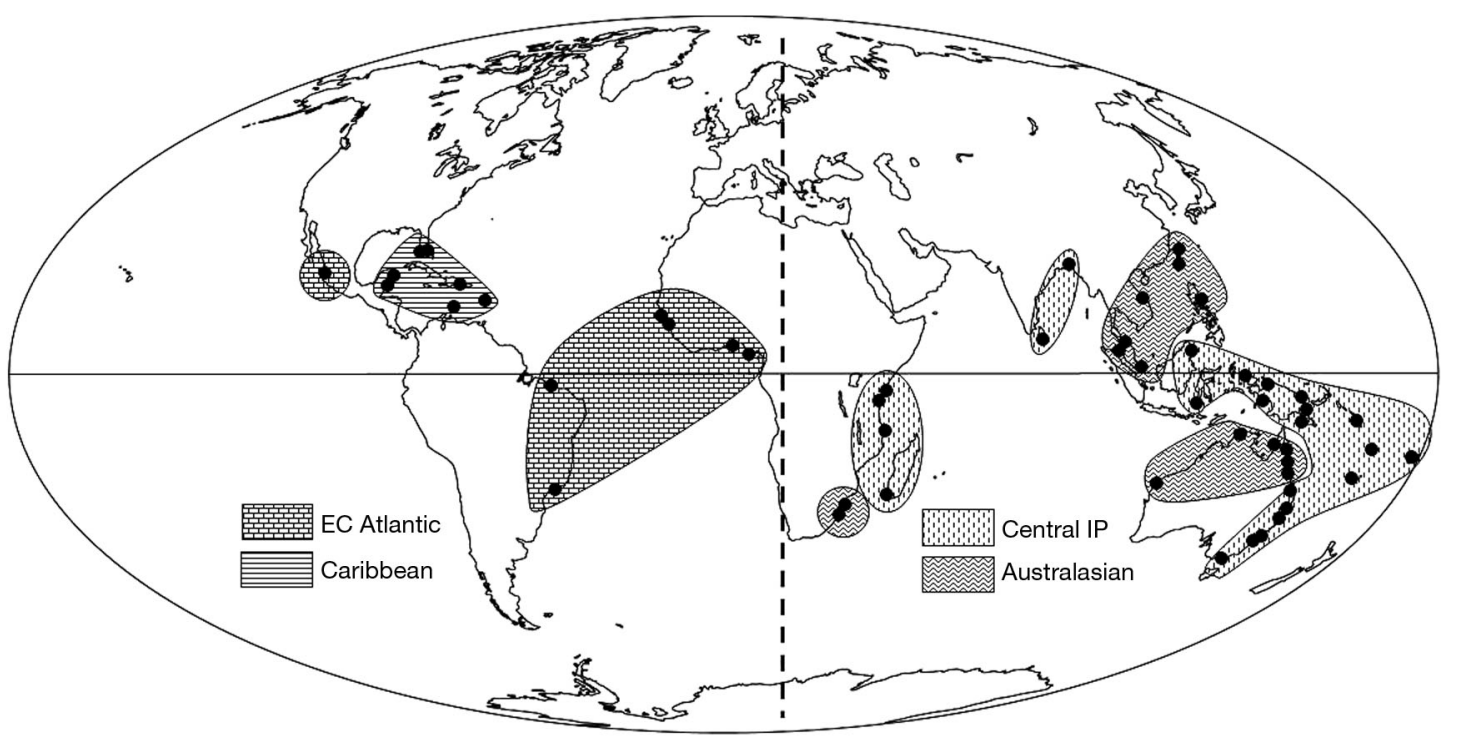

Fig. 3. Spatial extents of the 4 faunal groups (FGs) defined by the mCART (Fig. 2). EC: eastern central, IP: Indo-Pacific 


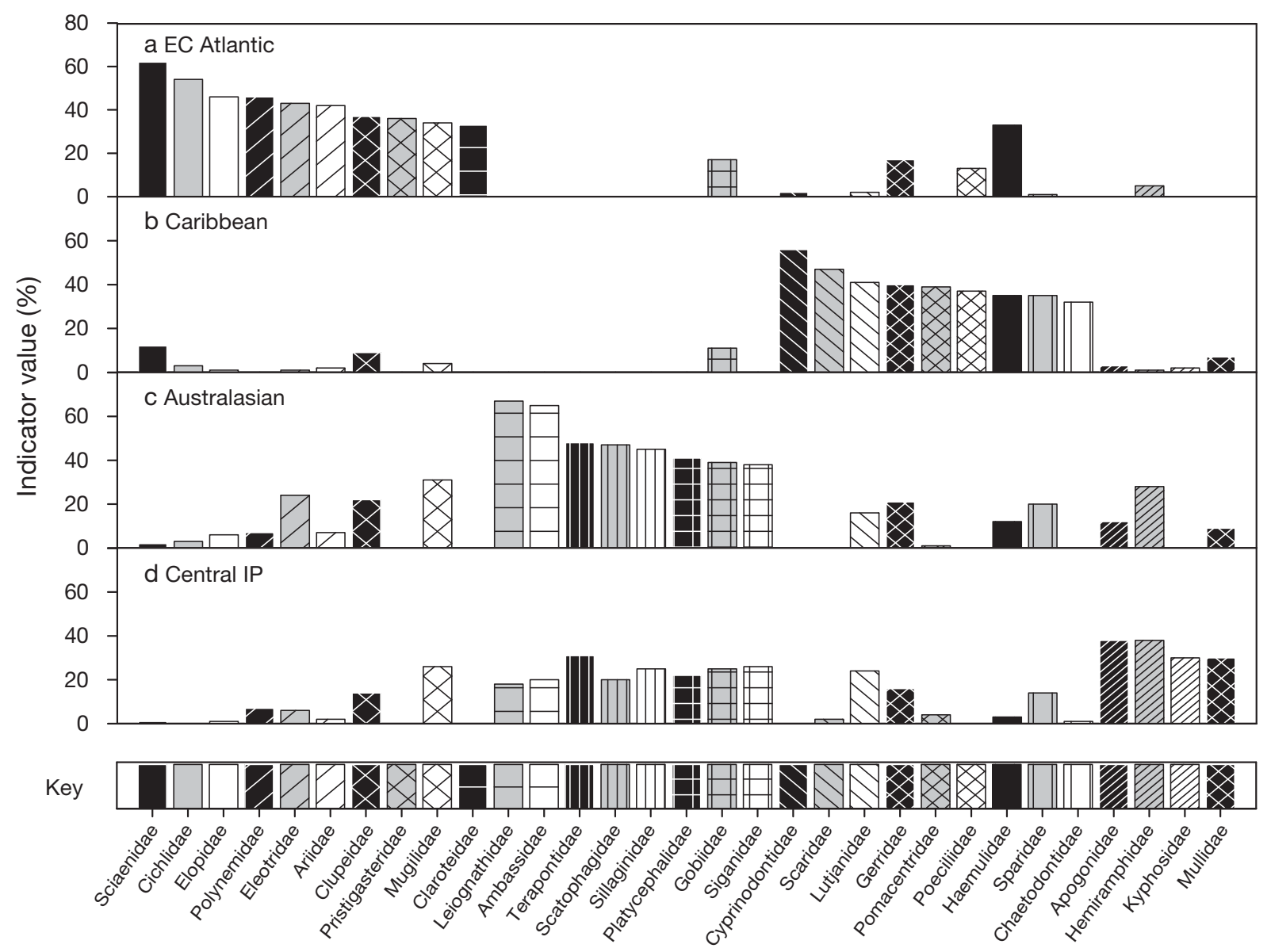

Fig. 4. Indicator values (\% of perfect indication) of species indicative of the faunal groups defined by the mCART (Fig. 2). EC: eastern central, IP: Indo-Pacific

nomic differences highlighted by the mCART analysis, the common mangrove families of the EC Atlantic and Australasian FGs had similar affinities, with major contributions from coastal families and the rest comprising families with freshwater affinities. In contrast, substantial components of both the Caribbean and Central IP FGs fauna had reef affinities, although the importance of families with freshwater affinities differed between these FGs. Comparison to Bellwood's (1996) coral reef fish consensus list (Table 2) reinforces the pattern of non-mangrove affinities. For common mangrove fish, families from the consensus list only occurred regularly ( $>40 \%$ of samples) in samples from the Caribbean (6/10) and to a lesser extent in the Central IP (4/10) and Australasian (3/10) FGs.

\section{Functional comparisons among the FGs}

Mangrove fish assemblages showed a consistent trophic mix that did not vary substantially among
FGs $\left(\chi^{2}=3.64\right.$, df $\left.=18, \mathrm{p}=0.9998\right)$, with macrobenthos and nekton feeding families dominating the trophic structure (Fig. 8a). Similarly, there was a consistent pattern across FGs $\left(\chi^{2}=3.14, \mathrm{df}=9, \mathrm{p}=\right.$ $0.9597)$ for the assemblages to be dominated by dem-

Table 2. Families from Bellwood's (1996) coral reef fish family consensus list that occurred in $>25 \%$ of samples in particular mangrove fish FGs. EC: eastern central, IP: Indo-Pacific

\begin{tabular}{|lcccc|}
\hline Fish family & $\begin{array}{c}\text { EC } \\
\text { Atlantic }\end{array}$ & Australasian & Caribbean & $\begin{array}{c}\text { Central } \\
\text { IP }\end{array}$ \\
\hline Acanthuridae & - & - & 47 & 31 \\
Apogonidae & - & 48 & - & 64 \\
Blenniidae & - & - & - & - \\
Carangidae & 72 & 87 & 58 & 79 \\
Chaetodontidae & - & - & 42 & - \\
Holocentridae & - & - & - & - \\
Labridae & - & - & - & - \\
Mullidae & - & 48 & 32 & 51 \\
Pomacentridae & - & - & 53 & - \\
Scaridae & - & - & 53 & - \\
\hline
\end{tabular}




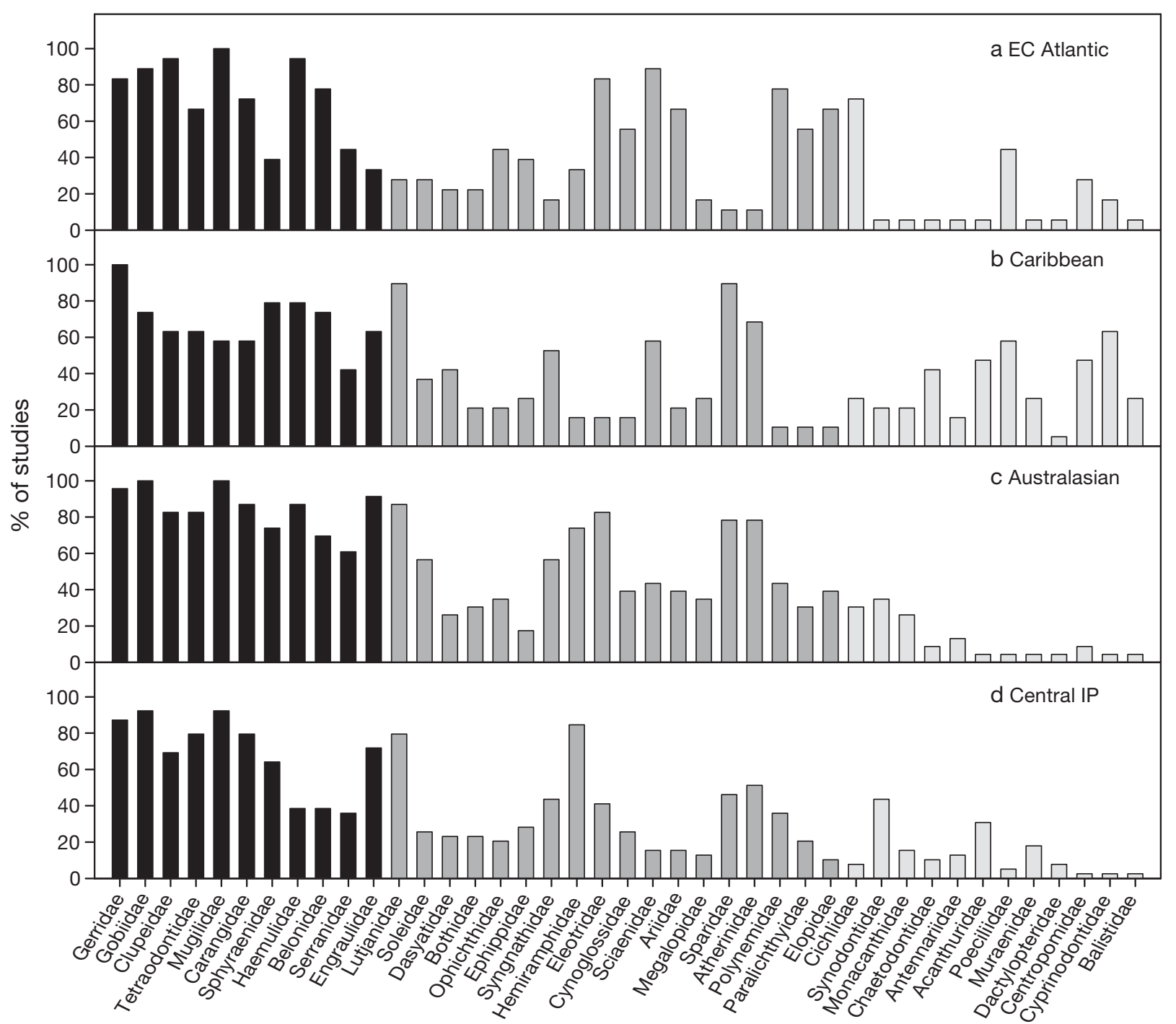

Fig. 5. Percentage of data sets for each faunal group (FG) in which families common to all FGs occurred. Minimum percentages of studies in any FG-black bars: $>30 \%$, dark grey bars: $<30 \%$ and $>10 \%$, light grey bars: $<10 \%$

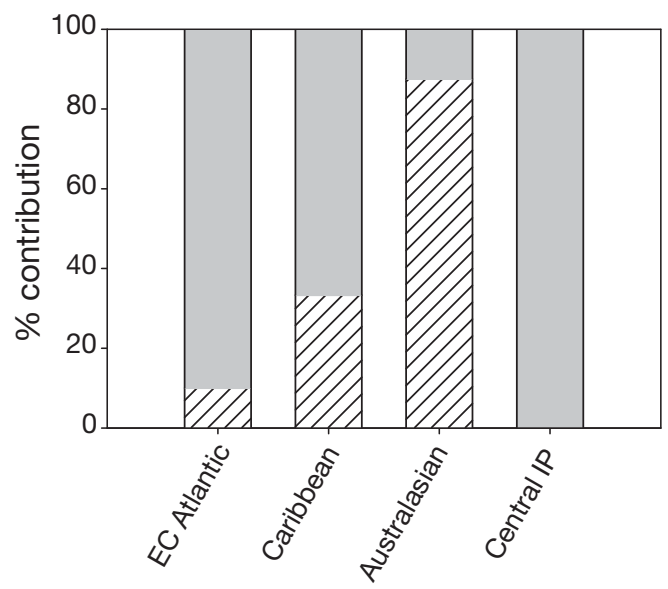

Fig. 6. Proportional contribution of families with widespread (grey-shaded) and restricted (hatched) distributions to the fish fauna of the 4 FGs. EC: Eastern central, IP: Indo-Pacific

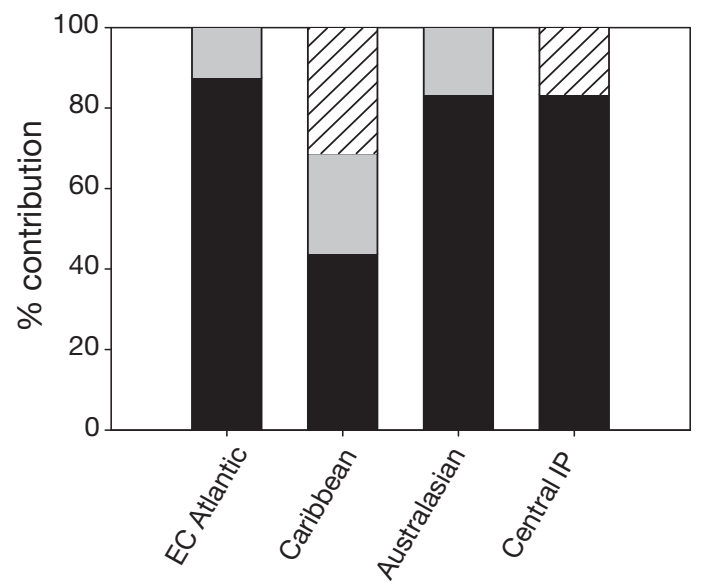

Fig. 7. Proportional contribution of non-mangrove associations of indicator families (black: coastal; grey: freshwater; white hatched: coral reef) to the fish fauna of the 4 FGs. EC: Eastern central, IP: Indo-Pacific 

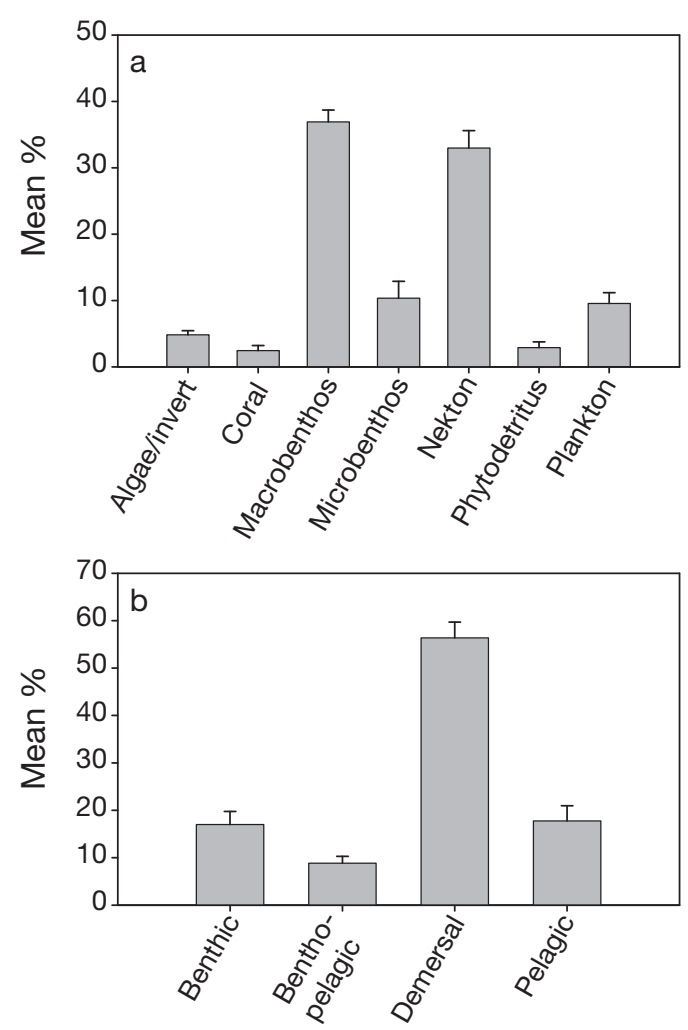

Fig. 8. Percentages (mean $+95 \% \mathrm{CI}$ ) of families (a) in different trophic groups, and (b) with different habits, for common mangrove fish families

ersal species (Fig. 8b). Nekton predator strategies were also conservative. A total of 64 families of nekton predators occurred in at least $25 \%$ of FGs (see Supplement S4). There was no evidence of differences in the strategy mix among the FGs $\left(\chi^{2}=5.87\right.$, $\mathrm{df}=9, \mathrm{p}=0.7638$ ), suggesting a commonality of functional prey acquisition strategies despite regional taxonomic differences. Foragers comprised the most common strategy across the FGs followed by ambushers, cursorial feeders and static habituators (Fig. 9).

\section{DISCUSSION}

Despite the occurrence of distinct FGs in different parts of the world, there was evidence of underlying taxonomic equivalence among mangrove fish assemblages. The total suite of mangrove fish comprised a restricted pool of 170 families, only about one-third of the $\sim 537$ families currently recognised (Eschmeyer 2010). Within this pool, there were substantial similarities among fish assemblages of mangrove ecosystems around the world, despite regional differences in faunal composition that are inevitable con-

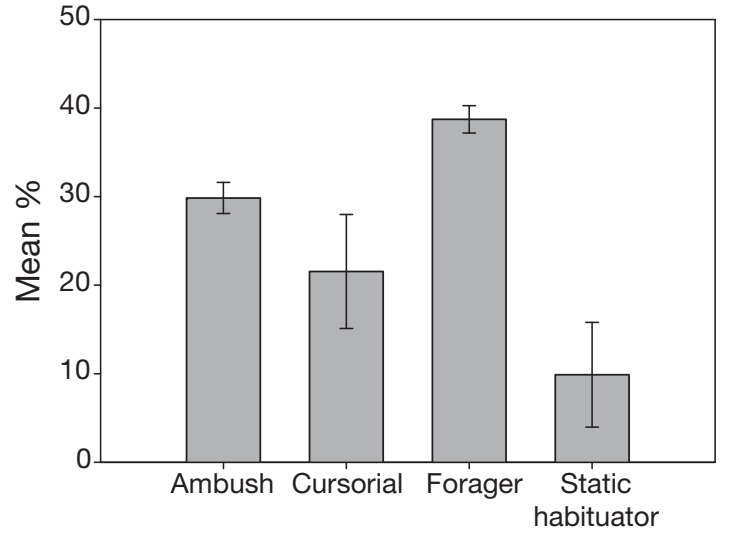

Fig. 9. Percentages (mean $\pm 95 \%$ CI) of nekton predators in each of 4 predator strategy categories

sequences of biogeographic distribution patterns. A total of 41 families were represented in all 4 mangrove FGs (Fig. 5), with many occurring in a substantial proportion of studies in each FG. For example, Gerridae, Gobiidae, Clupeidae, Tetraodontidae, Mugilidae, Carangidae, Sphyraenidae, Haemulidae, Belonidae, Serranidae and Engraulidae were found in at least $30 \%$ of studies from each FG. The consistent occurrence of this core group of families was impressive given the range of variation in the data base (different sampling gears, sampling intensities, scales of investigation and study foci as well as structural differences of the systems) that would be expected to add considerable noise to the data.

The idea of a core group of families typical of mangroves around the world parallels the idea of a 'consensus list' of coral reef fish families (Bellwood 1996) that predictably occur in high species richness on coral reefs around the world (Bellwood 1998). The present study adds some perspective to the debate flowing from the reef fish consensus list idea (Bellwood 1998, Robertson 1998). Bellwood (1998) concluded that the consensus list actually defined a shallow tropical-subtropical benthic fish fauna. Except in areas of the world where near-shore coral reefs are plentiful, there is little overlap between the reef fish consensus list and the common mangrove fish families, even though both are major shallow tropical/ subtropical benthic fish assemblages. This implies distinct ecosystem-based coral reef and mangrove fauna rather than simply a single shallow tropical/ subtropical assemblage.

Although the global occurrence of a core mangrove fauna supports the idea of faunal equivalence, this is not the complete story. Despite the core taxonomic similarity, it was possible to group mangrove fish assemblages into distinct FGs, each differenti- 
ated by the occurrence of characteristic indicator families. The 2 Atlantic FGs were spatially separated and had distinctly different characteristic fauna. In contrast, the Indo-Pacific FGs occurred as spatially interspersed groups and were characterised by differences in the importance of indicator families rather than clear differences in assemblage structure. Both FGs had a similar mix of indicator families, but most indicator values were substantially higher for the Australasian FG than the Central IP FG. Indicator values are a function of the uniqueness of occurrence of a family in an FG and how regularly the family occurs in samples from the FG. Consequently, lower indicator values for the Central IP than the Australasian FG for the families common to both reflect less consistent occurrence in the Central IP. This is presumably a reflection of the fact that the Central IP includes many isolated sites, while most of the Australasian sites occur mainly on continental land masses.

It is notable that whether studies only considered fish using mangrove forests themselves, or sampled more broadly and included associated habitats (e.g. seagrass beds and intertidal flats), was not an important factor in differentiating assemblages. Consequently, from a fish perspective, the 'mangrove ecosystem' appears to be defined at a whole-ofmangrove system level (i.e. the mangroves and associated habitats) rather than the scale of the mangrove forest. This accords well with the many fish studies that emphasise strong links between mangroves and other habitats (e.g. Robertson 1988, Nagelkerken \& van der Velde 2002, Dorenbosch et al. 2005, Sheaves \& Johnston 2008) and with studies showing high levels of faunal similarity over meso-spatial scales (Ley 2005, Sheaves 2006, Sheaves \& Johnston 2009). It also aligns with the idea that, in a functional sense, mangrove forests are part of a complexly interacting mosaic of habitats (Sheaves 2009, Hammerschlag \& Serafy 2010). The occurrence of a whole-of-mosaic, highly mobile fish assemblage implies that this fish assemblage performs a crucial role in interlinking elements of this mosaic into a functional mangrove ecosystem.

The fish indicative of FGs included families with both restricted and broad geographic ranges. Consequently, the among-region differences can be explained in part by differences in the balance between families with broad and restricted geographic ranges (i.e. by biogeographic patterns). However, that does not appear to be the only factor. There were notable differences in the non-mangrove affinities of common mangrove families. Both of the major groupings of FGs (Indo-Pacific vs. Atlantic) comprised an FG with only coastal and freshwater non-mangrove affinities and an FG that included families with reef affinities. The common mangrove families of EC Atlantic and Australasian FGs had similar nonmangrove affinities, with major contributions from coastal families and the rest comprising families with freshwater affinities. Both FGs comprise mainly large continental land masses with large rivers, so the contribution of fish with freshwater affinities accords with the ideas that the nature (Sheaves et al. 2007, Packett et al. 2009) and productivity (Abrantes \& Sheaves 2010) of coastal and estuarine mangrove environments as well as the compositions of mangrove fish fauna (Sheaves 1996, 1998) and fisheries (Dalzell et al. 1996) are influenced by the extent of inputs from large rivers. The Caribbean FG also had strong freshwater affinities, probably a reflection of large riverine influences on continental mangrove systems surrounding the Caribbean and the presence of large islands with substantial river systems, but also had a considerable proportion of common mangrove families with reef affinities. The common fauna of the Central IP FG had coastal and reef affinities but no families with freshwater affinities. The difference in fauna between the Central IP and Australasian FGs can probably be attributed to quite different environmental settings. The Indo-Pacific islands, which compose much of the Central IP FG, typically have extensive areas of coastal mangroves with coral reefs often in close proximity (Ellison 2009), while the continental settings of most of the Australasian FG include large areas of riverine mangroves (Spalding et al. 1997).

The contrast between the coral reef affinities of many characteristic families defining the Central IP and Caribbean FGs and the lack of the characteristic reef families characterising the Australasian and EC Atlantic FGs implies the occurrence of 2 distinctly different mangrove assemblages in both the IndoPacific and Atlantic groups. The presence of contrasting assemblages highlights fundamental differences in the environmental settings of the different FGs. This interaction between mangrove fish assemblages and environmental setting have been linked to differences in the provision of ecological services for particular cases (Dorenbosch et al. 2005). The present study suggests that such interactions are probably widespread, indicating that the fish assemblages of these contrasting FGs should be treated as separate entities when the role of mangroves as nurseries for coral reef fish is evaluated. This apparently elementary difference in settings could not be controlled for in the present study, in which the level of 
background information was very variable, but suggests that detailed, coordinated, broad-scale assessments of the impacts of geographic and geomorphologic setting on mangrove fish assemblages, and consequently on function, are needed.

From a taxonomic perspective, the evidence for equivalence is somewhat ambiguous; there are common faunal components, but as noted in previous comparisons of mangrove systems in different parts of the world (Barletta \& Blaber 2007), there are also clear taxonomic differences among definable faunal groupings. However, taxonomic similarity or difference is only one aspect of equivalence among ecosystem units and for many purposes is only of minor ecological importance compared to equivalence of function, the focus of most of the profound ecological questions (e.g. in the case of mangroves in their role as nurseries). The faunal differences among FGs suggest the potential for functional differences among the mangrove fish assemblages of the different regions. Notwithstanding, mangrove fish assemblages seemed to possess broadly homogeneous functional attributes; besides strong differences in affinities to other ecosystem types, there was no evidence of functional differences for any of the variables investigated. Across the data set, the fish assemblages are characteristic of mangrove systems as a whole rather than the mangrove forest per se, comprise both globally distributed families and families with local distributions and are dominated by fish with demersal habits that are mainly feeders on macrobenthos and nekton, with nekton feeders predominantly using foraging and ambush prey capture strategies (Baker \& Sheaves 2006). Consequently, despite taxonomic differences, mangrove fish assemblages demonstrate considerable functional equivalence, at least within the resolution of the data. The lack of functional change in the face of faunal variation suggests alternative taxa fulfilling roles determined by constraints of the ecosystem, rather than functional change in response to biogeographic pressures.

The circumglobal occurrence of a functionally consistent fauna characteristic of a particular ecosystem type implies ecosystem equivalence, which has implications that reach far beyond the mangrove ecosystem. At face value, it appears to provide a degree of validity for extrapolating understanding of processes and functions from one example of an ecosystem to another. However, despite the implied support for ecosystem equivalence, this is induction at its most extreme (Hurlbert 2004, Rothchild 2006), so great caution is needed when making any extrap- olation from one instance to a general principal. This is critical because ecologists regularly use information and understanding derived from an ecosystem unit in one part of the world to interpret the patterns they find in another example of the 'same' ecosystem type, often in an entirely different area. Accordingly, support for the idea of ecosystem equivalence must be set in context of the available data and limitations of the present study. (1) The present study was case specific; it only investigated one ecosystem type, so it might represent an anomalous situation. (2) Only 1 metric (consistency of fish assemblage) was used to measure ecosystem equivalence. The measuring tool can be critically important. For instance, Jenkins \& Buikema (1998) found that taxonomic resolution was an important determinant of whether differences were detected among zooplankton assemblages, and Smith et al. (1989), who used mangrove propagule predation as their measure, found differences around the world due to variations in forest type and seed predator guild. (3) The present study only considered 1 spatio-conceptual scale set; it focussed on the mangrove ecosystem (rather than, for instance, on its component parts, such as roots, leaves, soft substrates and channels), did not consider if the mangrove system was a 'natural unit' in its own right (rather than part of a larger 'ecosystem') and only considered 1 level of resolution (family). Consequently, there are still many important questions to be asked, such as, 'how consistent is this pattern for other ecosystem types?', 'how sensitive is the pattern to the way it is measured?', 'when would scientific resolution be fine enough for taxonomic differences to be important?', 'how consistent are similarities when different spatio-conceptual scales are considered?', and 'how consistent does structure and function need to be to allow useful extrapolation of ideas, processes and functions to other examples of an ecosystem type?' Clearly, although the example of mangrove fish assemblages gives some support for extrapolation among units of an ecosystem type, few studies have investigated this question, and the extensive and detailed body of work needed to support that practice does not exist. Many more studies, and deep evaluation of the outcomes and implications, are needed before the tacit assumption of equivalence can be confidently assumed. In fact, as more extensive understanding develops, the issues are more likely to move towards questions such as 'under what circumstances can equivalence be assumed?' and 'what limits should be placed on extrapolation from one example of an ecosystem type to others?' 
In depth evaluation of ecosystem equivalence is urgently needed because this untested assumption is central to the usefulness of every model based on data from another part of the world and the validity of every interpretation based on understanding extrapolated from a distant location.

Acknowledgements. I thank D. Bellwood, R. Johnston and 3 anonymous reviewers for their insightful comments that greatly improved this manuscript as well as all those who went through the arduous process of field work, analysis and publication to produce the data sets on which the present study is based.

\section{LITERATURE CITED}

Abrantes K, Sheaves M (2010) Importance of freshwater flow in terrestrial-aquatic energetic connectivity in intermittently connected estuaries of tropical Australia. Mar Biol 157:2071-2086

> Amaro T, Bianchelli S, Billett DSM, Cunha MR, Pusceddu A, Danovaro R (2010) The trophic biology of the holothurian Molpadia musculus: implications for organic matter cycling and ecosystem functioning in a deep submarine canyon. Biogeosciences 7:2419-2432

Baker R, Sheaves M (2006) Visual surveys reveal high densities of large piscivores in shallow estuarine nurseries. Mar Ecol Prog Ser 323:75-82

Barletta M, Blaber S (2007) Comparison of fish assemblages and guilds in tropical habitats of the Embley (Indo-West Pacific) and Caete (Western Atlantic) Estuaries. Bull Mar Sci 80:647-680

Bellwood D (1996) The Eocene fishes of Monte Bolca: the earliest coral reef fish assemblage. Coral Reefs 15:11-19

> Bellwood D (1998) What are reef fishes? - Comment on the report by D. R. Robertson: Do coral-reef fish faunas have a distinctive taxonomic structure? Coral Reefs 17:187-189

Breiman L, Friedman J, Olshen R, Stone C (1984) Classification and regression trees. Wadsworth International Group, Belmont, CA

Cheng SL, Fang HJ, Yu GR, Zhu TH, Zheng JJ (2010) Foliar and soil ${ }^{15} \mathrm{~N}$ natural abundances provide field evidence on nitrogen dynamics in temperate and boreal forest ecosystems. Plant Soil 337:285-297

Dalzell P, Adams TJH, Polunin NVC (1996) Coastal fisheries in the Pacific islands. Oceanogr Mar Biol Annu Rev 34: 395-531

De'ath G (2002) Multivariate regression trees: a new technique for modeling species-environment relationships. Ecology 83:1105-1117

De'ath G (2012) Package 'mv part' (v. 1.6-0). Multivariate partitioning. Available at http://cran.r-project.org/web/ packages/mvpart/mvpart.pdf (accessed 1 February 2012)

> Dorenbosch M, Grol MGG, Christianen MJA, Nagelkerken I, van der Velde G (2005) Indo-Pacific seagrass beds and mangroves contribute to fish density coral and diversity on adjacent reefs. Mar Ecol Prog Ser 302:63-76

Dufrene M, Legendre P (1997) Species assemblages and indicator species: the need for a flexible asymmetrical approach. Ecol Monogr 67:345-366

Ellison J (2009) Wetlands of the Pacific Island region. Wetlands Ecol Manage 17:169-206
Eschmeyer WN (2010) Catalog of Fishes, California Academy of Sciences. Electronic version available at http:// research.calacademy.org/research/ichthyology/catalog/ fishcatmain.asp (accessed 25 October 2012)

Froese R, Pauly D (eds) (2010) FishBase. www.fishbase.org Fuentes E (1976) Ecological convergence of lizard communities in Chile and California. Ecology 57:3-17

Hammerschlag N, Serafy J (2010) Nocturnal fish utilization of a subtropical mangrove-seagrass ecotone. Mar Ecol 31:364-374

Hammerschlag N, Morgan A, Serafy J (2010) Relative predation risk for fishes along a subtropical mangroveseagrass ecotone. Mar Ecol Prog Ser 401:259-267

Hurlbert S (2004) On misinterpretations of pseudoreplication and related matters: a reply to Oksanen. Oikos 104: 591-597

> Jenkins DG, Buikema AL (1998) Do similar communities develop in similar sites? A test with zooplankton structure and function. Ecol Monogr 68:421-443

$>$ Lamont BB (1995) Testing the effect of ecosystem composition structure on its functioning. Oikos 74:283-295

> Ley JA (2005) Linking fish assemblages and attributes of mangrove estuaries in tropical Australia: criteria for regional marine reserves. Mar Ecol Prog Ser 305:41-57

McDonald J (2009) Handbook of biological statistics, 2nd edn. Sparky House Publishing, Baltimore, MD

> Nagelkerken I, van der Velde G (2002) Do non-estuarine mangroves harbour higher densities of juvenile fish than adjacent shallow-water and coral reef habitats in Curacao (Netherlands Antilles)? Mar Ecol Prog Ser 245: 191-204

Nagelkerken I, Dorenbosch M, Verberk W, Chocheret de la Moriniere E, Van der Velde G (2000) Importance of shallow-water biotopes of a Caribbean bay for juvenile coral reef fishes: patterns in biotope association community structure and spatial distribution. Mar Ecol Prog Ser 202: 175-192

O'Neill R (2001) Is it time to bury the ecosystem concept? (with full military honours of course!). Ecology 82: 3275-3284

- Packett R, Dougall C, Rohde K, Noble R (2009) Agricultural lands are hot-spots for annual runoff polluting the southern Great Barrier Reef lagoon. Mar Pollut Bull 58: 976-986

Robertson AI (1988) Links between inshore fisheries resources and mangroves in tropical Australia: implications for coastal zone management in the South Pacific. Workshop on Pacific inshore fishery resources, S Pac Comm, Noumea

> Robertson D (1998) Do coral-reef fish faunas have a distinctive taxonomic structure? Coral Reefs 17:179-186

Rothchild I (2006) Induction deduction and the scientific method. The Society for the Study of Reproduction, Madison, WI (available at www.ssr.org)

Sheaves M (1996) Do spatial differences in the abundance of two serranid fishes in estuaries of tropical Australia reflect long-term salinity patterns? Mar Ecol Prog Ser 137:39-49

Sheaves M (1998) Spatial patterns in estuarine fish faunas in tropical Queensland: a reflection of interaction between long-term physical and biological processes? Mar Freshw Res 49:31-40

Sheaves M (2006) Scale-dependent variation in composition of fish fauna among tropical estuarine sandy embayments. Mar Ecol Prog Ser 310:173-184 
Sheaves M (2009) Consequences of ecological connectivity: the example of the coastal ecosystem mosaic. Mar Ecol Prog Ser 391:107-115

Sheaves M, Johnston R (2008) Influence of marine and freshwater connectivity on the dynamics of subtropical estuarine wetland fish metapopulations. Mar Ecol Prog Ser 357:225-243

Sheaves M, Johnston R (2009) Ecological drivers of spatial variability among fish fauna of 21 tropical Australian estuaries. Mar Ecol Prog Ser 385:245-260

Sheaves M, Baker R, Johnston R (2006) Marine nurseries and effective juvenile habitats: an alternative view. Mar Ecol Prog Ser 318:303-306

Sheaves M, Johnston R, Molony B, Shepard G (2007) The effect of impoundments on the structure and function of fish fauna in a highly regulated dry tropics estuary. Estuaries 30:507-517

Editorial responsibility: Janet Ley, St. Petersburg, Florida, USA
Sherman K, Aquarone MC (2004) UNEP Regional Seas Programme linked with large marine ecosystems assessment and management. LME Programme Office, Boston, MA

Smith T III, Chan H, McIvor C, Robblee M (1989) Comparisons of seed predation in tropical tidal forests from three continents. Ecology 70:146-151

Spalding M, Blasco F, Field C (eds) (1997) World mangrove atlas. The International Society of Mangrove Ecosystems, Okinawa

Tansley A (1935) The use and abuse of vegetational concepts and terms. Ecology 16:284-307

Vannote R, Minshall G, Cummins K, Sedell J, Cushing C (1980) The river continuum concept. Can J Fish Aquat Sci 37:130-137

Winterbourn M, Rounick J, Cowie B (1981) Are New Zealand stream ecosystems really different? N Z J Mar Freshw Res 15:321-328

Submitted: June 23, 2011; Accepted: April 17, 2012

Proofs received from author(s): July 27, 2012 